\title{
National Health Insurance
}

National Cancer Institute

\section{Source}

National Cancer Institute. National Health Insurance. NCI Thesaurus. Code C157357.

A system of health insurance benefits designed to cover a national population against

the costs of health care. It may be administered by the public sector, the private sector, or a combination of both. 